\title{
PERGAMON
}

www.elsevier.com/locate/watres

RAPID COMMUNICATION

\section{NOVEL CAKE CHARACTERISTICS OF WASTE-ACTIVATED SLUDGE}

\author{
R. M. WU ${ }^{1}$, D. J. LEE ${ }^{1,2 *}$, C. H. WANG ${ }^{2}$, J. P. CHEN ${ }^{2}$ and R. B. H. TAN ${ }^{2}$ \\ ${ }^{1}$ Department of Chemical Engineering, National Taiwan University, Taipei 10617, Taiwan ROC and \\ ${ }^{2}$ Department of Chemical and Environmental Engineering, National University of Singapore, 4, \\ Engineering Drive 4, Singapore 117576, Singapore
}

(First received 29 May 2000; accepted in revised form 18 October 2000)

\begin{abstract}
Breaking down the time limit constraints for conventional compression-permeation (C-P) cell test, this work has, for the first time, experimentally evaluated the cake characteristics of viable wasteactivated sludge subject to polyelectrolyte flocculation and to freeze/thaw treatment under a pressure range of $25-200 \mathrm{kPa}$. There exists a threshold pressure exceeding which the cake structure would significantly deteriorate. Also, the present biological sludge is a "super-compactible" sludge, whose compactibility is greater than most data ever reported in open literature. The information presented herein has implications to filter design/operation and can be used as a reference data set for examining the existing filtration theories. (C) 2001 Elsevier Science Ltd. All rights reserved
\end{abstract}

Key words - compression-permeability cell, porosity, specific resistance, yield stress

\section{INTRODUCTION}

The design and operation of mechanical dewatering apparatus for sludge, such as the belt filter press or the screw press, requires the knowledge of cake characteristics changes when subject to pressure compression and liquid permeation (Chang et al., 1997; Chang and Lee, 1998). The local cake porosity (ع) and the specific filtration resistance $(\alpha)$ are the most essential parameters in the applications of filtration theory to filter design and operation. Ruth (1946) introduced the compression-permeability cell (the $\mathrm{C}-\mathrm{P}$ cell) for measuring the porosity and the specific resistance as functions of applied pressure $(p)$. Many studies employed the C-P cell for analyzing the local properties in the filter cake, as briefly summarized in $\mathrm{Lu}$ et al. (1998a,b) and in $\mathrm{He}$ et al. (1997a). Despite the other technical drawbacks claimed for the C-P cell tests, the major difficulties to adopt the C-P cell tester in practice include the long testing time, say, up to 2-4 weeks for obtaining a complete set of data. Therefore, most C-P cell studies employed inorganic substance as their testing materials, like clay or calcium carbonate, to prevent possible quality changes during the relatively long testing time.

Waste-activated sludge (WAS) is a mixture containing bacteria and water, whose filter cake commonly exhibits high cake compressibility and a vast

*Author to whom all correspondence should be addressed. Fax: +886-2-2362-3040; e-mail: djlee@ccms.ntu.edu.tw amount of bound water (Wu et al., 1998). The increase in the applied pressure difference to filter a highly compactible sludge cake would not yield an increasing filtrate rate (Tiller et al., 1999; Lee et al., 2000). Mechanical dewatering is widely employed in WAS dewatering practice. However, the C-P cell data for the WAS are still largely lacking. Such a drawback is mainly attributed to the serious time limit for any biological sludge testing, for not exceeding 5-7 days before quality deterioration occurring (Sanin et al., 1994). With the same reasoning, Kwon (1995) used formalin to "fix" his biological sludge from degradation and completed his $\mathrm{C}-\mathrm{P}$ cell tests in 2 months. The effects of such a chemical treatment on the sludge cake characteristics are not clear.

He et al. (1997b) proposed a multifunctional test cell that could conduct filtration and C-P cell tests in the same apparatus. Since most of the sampling and consolidation procedures were automated with the assistance of a computer, one could perform each test in a relatively short period time (6-12 h). Hence, using this newly proposed $\mathrm{C}-\mathrm{P}$ cell tester, the collection of C-P cell data for biological sludge becomes feasible. This work for the first time reported the cake characteristics of WAS in both compression and permeation stages. Effects of adding polyelectrolyte and conditioned by freezing and thawing method were investigated. The fitting parameters of certain constitutive equations were evaluated and tabulated. The information presented herein could be used as a reference set of data in 
engineering design/operation or to check up with the existing guidelines for sludge dewatering management.

\section{MATERIALS AND METHODS}

\section{The sample}

Activated sludge samples ( $\mathrm{pH}$ 6.8-7.4) were taken from the reflux stream of Ulu Pandan Sewage Treatment Works, Singapore. The design of the Works is based on conventional activated sludge process using diffused air aeration system, having a total treatment capacity of $286,000 \mathrm{~m}^{3}$ per day. The dry solid content of sludge, determined by weighing and drying at $102^{\circ} \mathrm{C}$, was $0.24 \% \mathrm{w} / \mathrm{w}$. The chemical oxygen demand for the supernatant (COD) and that for the total sludge (TCOD) are 103 and $8500 \mathrm{mg} / \mathrm{L}$, respectively. After mixing and prior to settling, a small quantity of sludge-polymer aggregates in the vessel was transferred carefully into the fresh electrolyte at the same $\mathrm{pH}$ and electrolyte concentration as the original electrolyte. Zeta potentials of aggregates were then measured by the zeta meter (Zeter-Meter System 3.0, ZeterMeter Inc., USA). The result for original sludge flocs read $-19.3 \mathrm{mV}$. The particle size distribution was determined by Sedigraph $5100 \mathrm{C}$ (Micromeritics) as a monodispersed distribution with a mean diameter of approximately $145.7 \mu \mathrm{m}$. The true solid density was measured by Accupyc Pycometer 1330 (Micromeritics), giving a measure of $1378 \mathrm{~kg} / \mathrm{m}^{3}$ with a relative deviation of less than $0.5 \%$. Capillary suction apparatus as described in Lee and Hsu $(1992,1993)$ was employed to estimate the sludge filterability. The capillary suction time (CST) for original sludge is $62 \mathrm{~s}$.

The sludge was subject to chemical or physical conditioning. For chemical conditioning, the cationic polyelectrolyte indicated as polymer T-3051 was obtained from KaiGuan Inc., Taiwan. The polymer T-3051 is a polyacrylamide with an average molecular weight of $10^{7}$, and a charge density of $20 \%$. The mixing unit was a magnetic stirrer. The weighed powder was first suspended in distilled water. Solution of the polymer solution was then gradually poured into the mixing vessel with $500 \mathrm{rpm}$ of stirring for $25 \mathrm{~min}$. The settleability of the chemical-conditioned sludge was determined using hindered settling tests performed in tubes of diameter $2.5 \mathrm{~cm}$ and height $18.5 \mathrm{~cm}$. The zone settling velocity (ZSV) could be obtained by linear regression of the interface height versus time data for the constant-rate period with a regression coefficient higher than 0.98 . Other experimental details could be found in Chen et al. (1996). The ZSVs for original sludge, and for those conditioned at 50,100 and $200 \mathrm{ppm}$ of polyelectrolyte are $800,930,4880$, and $2810 \mu \mathrm{m} / \mathrm{s}$, respectively. According to the settling test, the application of polyelectrolyte could markedly enhance the zone settling velocity, while the so-called "optimal dose" for the present activated sludge could be identified as around $100 \mathrm{ppm}$ of polyelectrolyte.

Freeze/thaw conditioning is an efficient method of changing floc structure and reducing the bound water content in sludge (Lee and Hsu, 1994). The sample is placed in a stainless-steel vessel measuring $25 \mathrm{~cm}$ in diameter, $0.15 \mathrm{~cm}$ thick and $25 \mathrm{~cm}$ high. The vessel is immersed for $48 \mathrm{~h}$ in a freezing pool at a temperature of $-15^{\circ} \mathrm{C}$. After freezing, the sample was thawed at room temperature for another $12 \mathrm{~h}$. Such an experimental condition was chosen for providing sufficiently low freezing speed for sufficient conditioning of the sludge (Hung et al., 1997).

\section{$C-P$ cell and test}

Figure 1 illustrates the schematic diagram of the $\mathrm{C}-\mathrm{P}$ cell and other supportive apparatus. The load at the top $(p)$ and

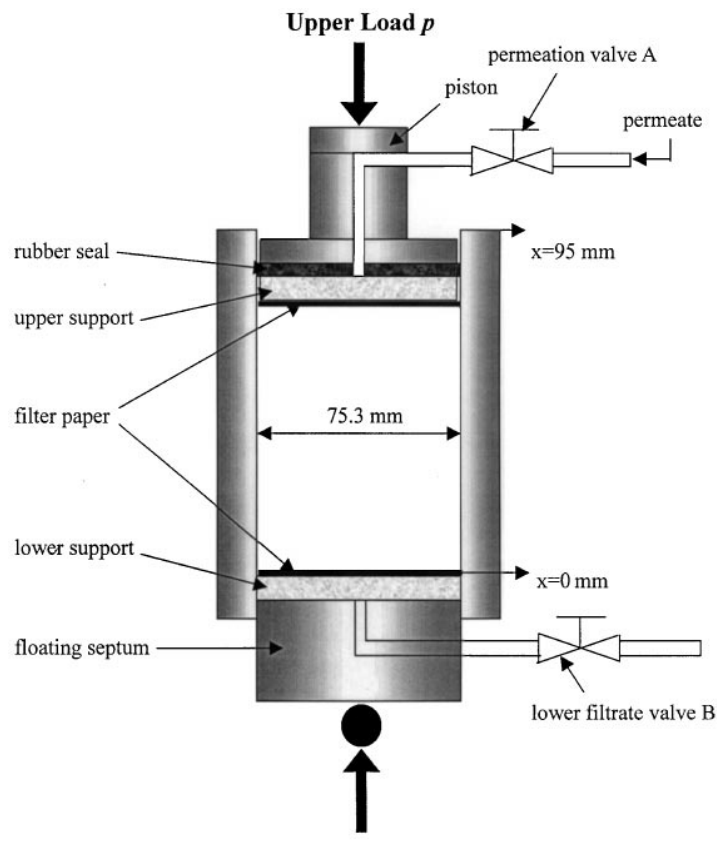

Lower Load $p_{T}$

Fig. 1. Compression-permeation cell used in this work.

the transmitted pressure to the bottom surface $\left(p_{T}\right)$ are measured together with the cake height during each test. The cell has a cylinder made of stainless steel of inner diameter $75.3 \mathrm{~mm}$. A complete $\mathrm{C}-\mathrm{P}$ cell test comprises two stages: the compression stage and the permeation stage. The cell could track both stages since all data from pressure transducers as well as from the displacement measurement were automatically sent to a computer for storage and processing.

Prior to the C-P cell test the septum was first filled with filtrate. The slurry was carefully poured into the cylinder and drained to form a saturated, wet cake. The piston was positioned at the top of the formed cake, through which the mechanical force was applied. During the compression the valve-A (permeation valve) was close and valve-B open, which allows the drainage of the filtrate. Before and after having reached mechanical equilibrium with the applied load, the thickness of compressed cake was continuously measured and recorded. Then the permeation test was conducted by allowing the filtrate to flow from a constant-head reservoir through the valve-A and the cake. An electronic balance measured the filtrate weight. With the flow rate and the pressure drop data, the specific resistance of filtration of cake could be determined. The temperatures during testing were used to correct the viscosity of filtrate.

The pressure range under investigation is $25-200 \mathrm{kPa}$. The choice of such a pressure range for test is attributed to the following two reasons. Firstly, in preliminary tests at the applied pressure of $50 \mathrm{kPa}$, the cake structure of activated sludge reveals a significant collapse, which had not occurred at the test of the less pressure. Hence the lower limit for applied pressure under investigation is set at $25 \mathrm{kPa}$. Moreover, since the total testing time has to be limited within 7 days, the upper pressure limit was taken as $200 \mathrm{kPa}$. Although the practical range for sludge dewatering could be up to $500-700 \mathrm{kPa}$, however, as the present experimental data illustrated, the basic characteristics for cake properties would remain unchanged at pressures exceeding $200 \mathrm{kPa}$. 


\section{RESULTS AND DISCUSSION}

\section{Compression test}

Figure 2 illustrates the time evolutions for the cake thickness. Apparently, at $p=25 \mathrm{kPa}$, the cake could be only mildly compressed. For the original sludge, the cake reaches equilibrium at around $30,000 \mathrm{~s}$. For flocculated sludges, on the other hand, the mechanical equilibrium has been established rather rapidly. Also, the cake thickness reduces for less than $10 \%$. At a higher load of $50 \mathrm{kPa}$, the cake structure starts to collapse markedly. The reduction in cake thickness could be as high as $80-90 \%$. Although the consolidation times needed for flocculated sludge are still much less than the original sludge, they are 3-5 times longer than those at $25 \mathrm{kPa}$. Further increase in the applied pressure would continuously compress the cake. However, no qualitative cake characteristic changes had been observed at the elevated pressures. Such an observation indicates that there exists a threshold pressure exceeding which the cake structure would significantly deteriorate, attributed to the network structure built over the entire sludge. The compaction characteristics for the present WAS under low applied load (like in sedimentation) and for that under higher load (like filtration, centrifugation, and consolidation) would be very different.

The trend for the consolidation curves less than the threshold pressure is opposite to that for greater than the threshold pressure. At 20 and $50 \mathrm{kPa}$, the cake becomes the stiffest at the dosage of $100 \mathrm{ppm}$. However, exceeding the threshold pressure, the trend reverses. The optimal dosage would yield the fastest dewatering, which corresponds to the previous studies with clay slurries (Chu and Lee, 2000). The cake compaction at applied load less than the threshold pressure would behave very differently from those at elevated pressures.

\section{Permeation test}

Figures 3(a) and (b) illustrate, respectively, the measured $\varepsilon-p_{\mathrm{M}}$ and the $\alpha-p_{\mathrm{M}}$ data, where $p_{\mathrm{M}}$ is the log-mean pressure difference defined as

$$
p_{\mathrm{M}}=\frac{p-p_{\mathrm{T}}}{\ln \left(p / p_{\mathrm{T}}\right)}
$$

Firstly, the cake porosity $(\varepsilon)$ decreases with increasing solid pressure, which correlates with the common knowledge that a higher pressure leads to a more compacted cake (Fig. 3(a)), whence a greater specific resistance of the filter cake $(\alpha)$ (Fig. 3(b)). Secondly, at a prescribed pressure, although with some data scattering, the cake porosity first decreases with polyelectrolyte dose, after reaching minimum at the optimal dose $(100 \mathrm{ppm})$, and then increases in the overdosing regime. Restated, the presence of polyelectrolyte would yield a more compact structure but easier to permeate sludge cake. Such an observation should be attributed to the existence of a vast amount of bound water that changes the "effective" porosity for the filter cake (Lee and Hsu, 1995). For original sludge, for example, the effective porosity of cake would be much less than demonstrated if the bound water has been taken into account. Such an information is not available for the present $\mathrm{C}-\mathrm{P}$ cell test. Finally, the freeze/thaw treatment would yield a more compact and easier to permeate sludge cake when compared with the original sludge. The effects are not as significant as that for chemical conditioning for the present WAS.

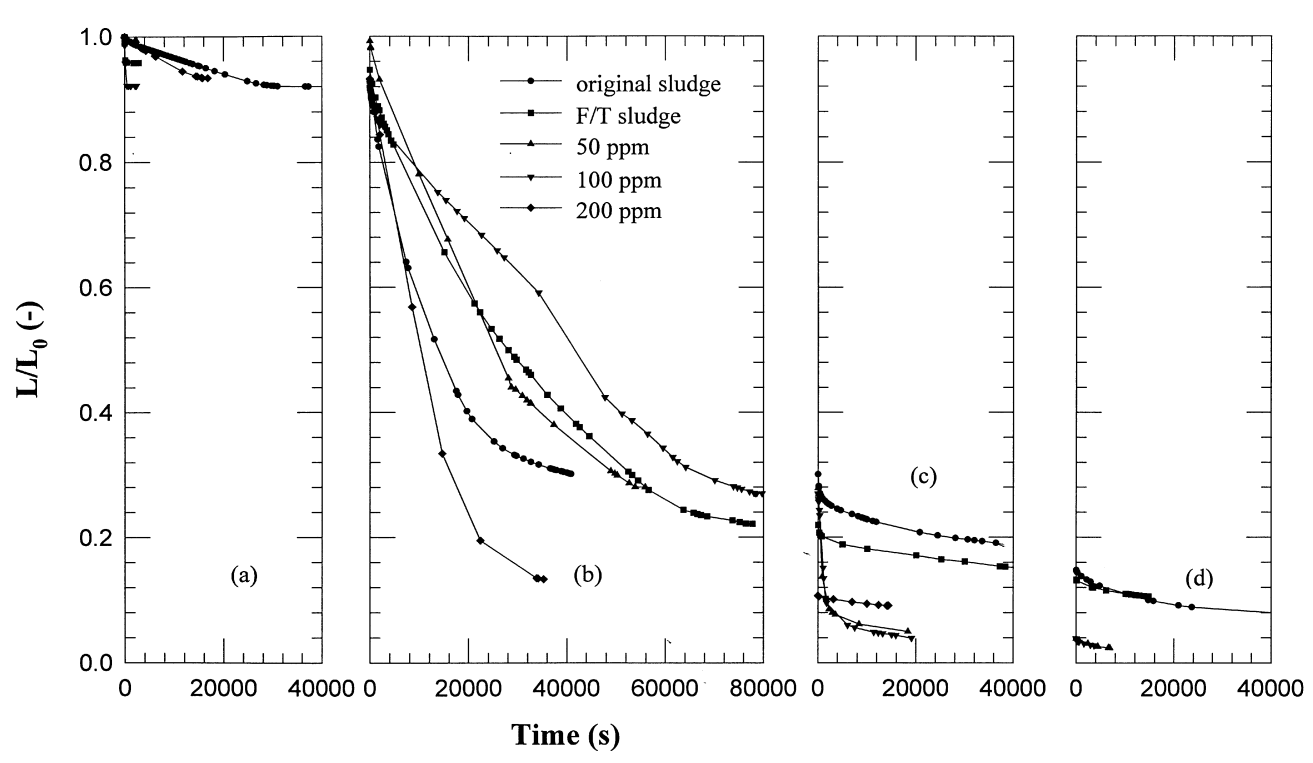

Fig. 2. The time evolutions for cake thickness under axial loads: (a) $p=0.25 \times 10^{5} \mathrm{~Pa}$; (b) $p=0.5 \times 10^{5} \mathrm{~Pa}$; (c) $p=1 \times 10^{5} \mathrm{~Pa}$; (d) $p=2 \times 10^{5} \mathrm{~Pa}$. The initial cake thickness $\left(L_{0}\right)$ is $2.0 \mathrm{~cm}$. 

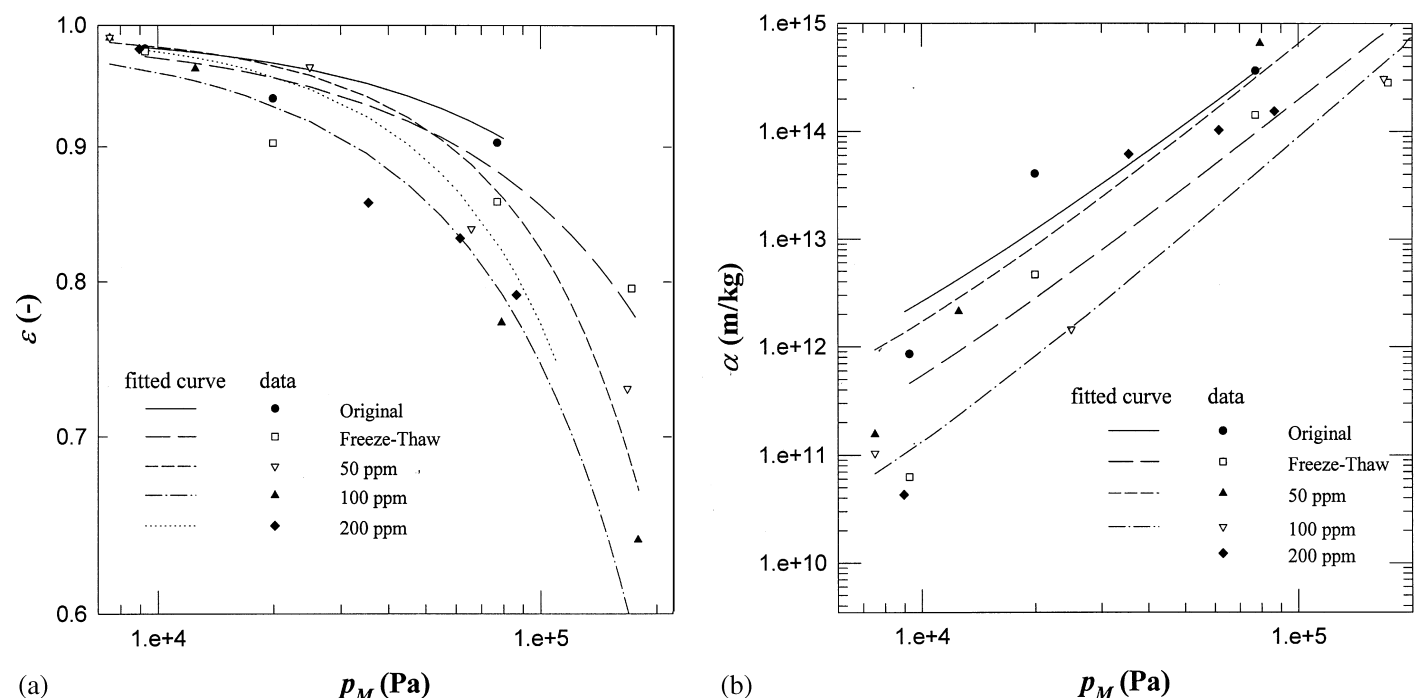

Fig. 3. (a) Porosity ( $\varepsilon$ ) versus pressure of the filter cake. (b) Specific filtration resistance $(\alpha)$ versus pressure of the filter cake.

To correlate the measured cake characteristics as functions of applied pressure, like porosity and specific resistance to filtration, various constitutive equations had been previously proposed in the literature (Lee and Wang, 2000). Tiller and Leu (1980) proposed the following constitutive equations as follows:

$$
\begin{gathered}
\alpha=\alpha_{0}\left(1+\frac{p}{p_{\mathrm{a}}}\right)^{n} \\
1-\varepsilon=\left(1-\varepsilon_{0}\right)\left(1+\frac{p}{p_{\mathrm{a}}}\right)^{\beta} \\
k=k_{0}\left(1+\frac{p}{p_{\mathrm{a}}}\right)^{-\delta}
\end{gathered}
$$

In Equations (1)-(3), $\varepsilon_{0}, \alpha_{0}$ and $k_{0}$ are the cake porosity, specific resistance, and permeability under null-stress condition, and $p_{\mathrm{a}}, \beta, n$, and $\delta$ are the fitting parameters. Notably, $\delta=\beta+n$ for a specific cake. Therefore, only two of the three equations in Equations (1)-(3) are independent. Tiller and Leu (1980) proposed a graphic method to determining all parameters in Equations (1) and (2).

Table 1 lists the best-fitting parameters, showing a $\delta$ value greater than 3.6. The presence of polyelectrolyte would yield an even greater $\delta$ value (exceeding 4.0). Literature works regarded the sludge cake with $\delta>1$ as "highly compactible" (Tiller and Kwon, 1998). This work demonstrates that the present WAS is a "super-compactible" sludge. In reality, the compactibility noted for this WAS is much higher than the most sludges ever reported. For example, $\mathrm{La}$ Heij (1994) estimated $\delta=2.3$ and Kwon (1995) gave $\delta=1.66$ for their activated sludges. Such a discre-
Table 1. Model parameters in equations (1)-(3). $\delta=\beta+\mathrm{n}$

\begin{tabular}{lcrrrrc}
\hline Polymer dose & $\beta$ & $n$ & $\delta$ & $\begin{array}{c}p_{\mathrm{a}} \\
(\mathrm{kPa})\end{array}$ & $\varepsilon_{0}$ & $\begin{array}{c}\alpha_{0} \\
\left(10^{10} \mathrm{~m} / \mathrm{kg}\right)\end{array}$ \\
\hline Original & 0.83 & 2.7 & 3.5 & 3.0 & 0.993 & 5.0 \\
$50 \mathrm{ppm}$ & 1.10 & 2.9 & 4.0 & 3.3 & 0.995 & 3.0 \\
$100 \mathrm{ppm}$ & 0.88 & 3.1 & 4.0 & 2.6 & 0.994 & 0.1 \\
$200 \mathrm{ppm}$ & 1.10 & $>3.1$ & $>4.2$ & 2.6 & 0.995 & $\mathrm{NA}$ \\
$\mathrm{F} / \mathrm{T}$ & 0.78 & 2.8 & 3.6 & 2.5 & 0.993 & 0.6 \\
\hline
\end{tabular}

pancy might be arisen from the quality changes for La Heij and Kwon's sludges during the C-P cell test. The present $\mathrm{C}-\mathrm{P}$ cell could provide the cake characteristics for viable activated sludge within a relatively short period of time.

The recognition of the "super-compactibility" of the WAS suggests that, owing to the formation of a "skin layer" close to the septum, to simply increase the applied pressure would not yield a greater filtrate flow rate. The basic equations to design and operation of filters would hence be very different from those adopted for those of low-to-medium compactibility (Tiller and Kwon, 1998, Tiller et al., 1999; Lee et al., 2000). In filtration chamber, a lowbut-sufficient pressure drop should thereby be adopted. Simply raising the applied pressure could not help in enhancing the filter performance.

\section{CONCLUSIONS}

All tests regarding biological sludge have to be completed within 5-7 days for preventing the quality deterioration. However, a conventional compression-permeation (C-P) cell test commonly required a relatively long period of time. With the assistance 
of a newly proposed C-P cell by $\mathrm{He}$ and co-workers, this work has, for the first time, experimentally evaluated the cake characteristics of waste-activated sludge subject to polyelectrolyte flocculation and to freeze/thaw treatment under a pressure range of 25 $200 \mathrm{kPa}$. Compression tests indicate the existence of a threshold pressure exceeding which the cake structure would be significantly deteriorated. The compaction characteristics for the waste activated sludge under low applied load and for that under higher load would be very different.

In permeation test, the cake porosity was noted to decrease with increasing applied load, whence yielding a greater specific resistance of the filter cake. However, the presence of polyelectrolyte would lead to a more compact structure but easier to permeate sludge cake. The effects of freeze/thaw treatment are milder than the chemical conditioning adopted herein. Using the correlation proposed by Tiller and Leu (1980), the present WAS was identified as a "supercompactible" sludge, whose compactibility was greater than the most data ever reported in the literature. The chemical conditioning would further increase its compatibility. Thus, the cake characteristics of the present biological sludge would shed out the benefit for raising the applied pressure in filtration practice. The information presented herein could be used as a reference set of data in engineering design/operation or to check up with the existing guidelines for sludge dewatering management.

Acknowledgements -DJL wishes to thank National University of Singapore for appointing him as a senior fellow during June to September, 1999.

\section{REFERENCES}

Chang I. L., Chu C. P., Lee D. J. and Huang C. (1997) Effects of polymer dose on filtration followed by expression characteristics of clay slurries. J. Colloid Interface Sci. 185, 335-342.

Chang I. L. and Lee D. J. (1998) Ternary expression stage in biological sludges dewatering. Water Res. 32, 905-914.

Chen G. W., Chang I. L., Hung W. T. and Lee D. J. (1996) Regimes of zone settling of waste activated sludge. Water Res. 30, 1844-1851.

Chu C. P. and Lee D. J. (2000) Expression characteristics of polyelectrolyte flocculated sludges. J. Chin. Inst. Chem. Engrs. 31, 321-331.
He D. -X., Tan R. B. H. and Tien C. (1997a) An overview of investigations on filter cake characteristics. Adv. Filtr. Sep. Technol. 11, 404-411.

He D.-X., Tan R. B. H. and Tien C. (1997b). An investigation of the filter cake characteristics in a modified compression-permeability cell. 1997 A.I.Ch.E. Annual Meeting, Los Angeles, USA.

Hung W. T., Feng W. H., Tsai I. H., Lee D. J. and Hong S. G. (1997) Unidirectional freezing of waste activated sludge: radial freezing versus vertical freezing. Water Res. 31, 2219-2228.

Kwon J. H. (1995) Effects of compressibility and cake clogging on sludge dewatering characteristics. Ph.D. Dissertation, Seoul National University, Seoul, Korea.

La Heij E. J. (1994) An analysis of sludge filtration and expression. Ph.D. Dissertation, Technische Universiteit Eindhoven, Eindhoven, The Netherlands.

Lee D. J. and Hsu Y. H. (1992) Fluid flow in capillary suction apparatus. Ind. Eng. Chem. Res. 31, 2379-2384.

Lee D. J. and Hsu Y. H. (1993) Cake formation in capillary suction apparatus. Ind. Eng. Chem. Res. 32, 1180-1185.

Lee D. J. and Hsu Y. H. (1994) Fast freeze/thaw process on excess activated sludges: Floc structure and sludge dewaterability. Environ. Sci. Technol. 28, 1444-1449.

Lee D. J. and Hsu Y. H. (1995) Measurement of bound water in sludges: a comparative study. Wat. Environ. Res. 67, 310-317.

Lee D. J., Ju S. P., Kwon J. H. and Tiller F. M. (2000) Filtration of highly compactible filter cake: variable internal flow rate. A.I.Ch.E. J. 46, 110-118.

Lee D. J. and Wang C. H. (2000) Theories of cake filtration and consolidation and implications to sludge dewatering. Water Res. 34, 1-20.

Lu W. M., Huang Y. P. and Hwang K. J. (1998a) Methods to determine the relationship between cake properties and solid compressive pressure. Sep. Purif. Technol. 13, 9-23.

Lu W. M., Huang Y. P. and Hwang K. J. (1998b) Stress distribution in a confined wet cake in the compressionpermeability cell and its application. Powder Technol. 97, $16-25$.

Ruth B. F. (1946) Correlating filtration theory with industrial practice. Ind. Eng. Chem. 38, 564-571.

Sanin F. D., Vesilind P. A. and Martel C. J. (1994) Pathogen reduction capability of freeze/thaw sludge conditioning. Water Res. 28, 2393-2398.

Tiller F. M. and Kwon J. H. (1998) Role of porosity in filtration-XIII-behavior of highly compactible cakes. A.I.Ch.E. J. 44, 2159-2167.

Tiller F. M. and Leu W. F. (1980) Basic data fitting in filtration. J. Chin. Inst. Chem. Engrs. 11, 61-70.

Tiller F. M., Lu R., Kwon J. H. and Lee D. J. (1999) Variable liquid flow rate in compactible filter cakes. Water Res. 33, 15-23.

Wu R. M., Feng W. H., Tsai I. H. and Lee D. J. (1998) An estimate of waste activated sludge floc permeability: a novel hydrodynamic approach. Water Environ. Res. 70, $1258-1264$. 